\title{
Um estudo sobre a utilização de sistemas, programas e ferramentas da qualidade em empresas do interior de São Paulo
}

\author{
José Augusto de Oliveira ${ }^{\mathrm{a} *}$, Jeniffer de Nadae, \\ Otávio José de Oliveirac, Manoel Henrique Salgado ${ }^{\mathrm{d}}$ \\ a*joseao@feb.unesp.br, UNESP, Brasil \\ bjnadae@gmail.com, UNESP, Brasil \\ cotavio@feb.unesp.br, UNESP, Brasil \\ dhenri@feb.unesp.br
}

\begin{abstract}
Resumo
0 desenvolvimento e implantação de sistemas de gestão da qualidade e o uso de programas e ferramentas da qualidade são algumas das opções mais utilizadas pelos gestores para aumentar a competitividade de suas empresas. Nesse contexto, o objetivo deste artigo é apresentar o resultado de uma pesquisa tipo survey em que se verificaram e analisaram as principais características do processo de certificação $1 S 09001$, seus benefícios, suas dificuldades e quais programas e ferramentas da qualidade são utilizados em 236 empresas do interior do Estado de São Paulo. A pesquisa revelou que a certificação 1SO 9001 gera benefícios significativos às organizações, tais como: melhoria dos processos internos e nos seus produtos; aumento da satisfação dos clientes; diminuição do número de não conformidades e de devoluções; aumento da produtividade e do lucro; melhoria no gerenciamento dos recursos e valorização da imagem da empresa no mercado. Ela também ratificou a importância da utilização dos programas e ferramentas da qualidade como forma de as empresas se adequarem melhor aos requisitos da norma 1 SO 9001. As dificuldades de desenvolvimento e implantação desses sistemas não se confirmaram para a amostra pesquisada. Apenas a resistência à mudança, dentre todas apresentadas, mereceu destaque para os pesquisados.

Palavras-chave

Sistema de gestão da qualidade. Programas da qualidade. Ferramentas da qualidade. $1 S 0$ 9001. Interior do Estado de São Paulo.
\end{abstract}

\section{Introdução}

As organizações empresariais, independentemente de sua área de atuação, estão enfrentando uma realidade dinâmica, sem fronteiras econômicas definidas, muito competitiva, com clientes cada vez mais exigentes e legislações locais crescentemente mais restritivas em relação à qualidade de produtos e serviços, meio ambiente e saúde do trabalhador. Esse cenário pressiona-as a se reestruturarem na direção da modernização técnica e gerencial (LAGROSEN; LAGROSEN, 2003; KILBOURNE, 2004; LAGROSEN, 2007; TONINI; CARVALHO; SPINOLA, 2008; OLIVEIRA; OLIVEIRA, 2008).

Nesse contexto, a gestão da qualidade apresenta-se como uma interessante alternativa para dotar as empresas de mecanismos para controlar seus processos e melhorá-los continuamente de forma a atender e superar as expectativas do consumidor, promovendo, dessa forma, a melhoria organizacional e, por conseguinte, aumentando sua competitividade (GALDÁMEZ; CARPINETTI; GEROLAMO 2009; OLIVEIRA; MARTINS, 2008).

Os sistemas de gestão da qualidade (SGQs) são um meio para a introdução e sistematização da filosofia e dos procedimentos da qualidade nas organizações. Seu enfoque é no desenvolvimento, implementação, padronização, manutenção e melhoria da qualidade de processos, produtos e serviços. A forma de SGQ mais comumente adotada pelas organizações é baseada na norma $1 S 09001$ 
(GONZALEZ; MARTINS, 2007; DEPEXE; PALADINI, 2008).

Já os programas e ferramentas da qualidade são os elementos que permitem operacionalizar efetivamente os preceitos da gestão da qualidade contidos nos sistemas de gestão da qualidade 1SO 9001. Eles são os instrumentos utilizados para o desenvolvimento, medição, análise e melhoria da qualidade nas organizações. Assim, permitem a identificação e solução dos principais problemas organizacionais e, por este motivo, são importantes instrumentos de diferenciação organizacional (BAMFORD; GREATBANKS, 2005; ALSALEH, 2007).

Contudo, a utilização tanto dos SGQs como dos programas e ferramentas enfrenta uma série de dificuldades em face das características do mercado brasileiro e de suas organizações: deficiências em relação à qualificação de mão de obra, baixo fôlego financeiro de médias e pequenas empresas e ausência de programas públicos e/ou coletivos de fomento da competitividade empresarial (GRAEL; OLIVEIRA, 2010).

Segundo o Instituto Brasileiro de Geografia e Estatística - IBGE (INSTITUTO..., 2009a), o Produto Interno Bruto (PIB) do Brasil em 2007 foi de aproximadamente $\mathrm{R} \$ 2,37$ trilhões, sendo só o Estado de São Paulo responsável por cerca de R\$ 802 bilhões. A cidade de São Paulo contribuiu com aproximadamente $\mathrm{R} \$ 282$ bilhões, e o resto do Estado, parte do objeto deste estudo, com cerca de R\$ 519 bilhões.

De acordo com o Instituto Nacional de Metrologia, Normalização e Qualidade Industrial - INMETRO (2009b), o Brasil possui 8.731 certificações ISO 9001 válidas, sendo 4.034 delas de unidades empresariais do Estado de São Paulo, onde 1.027 são da cidade de São Paulo e 3.007 do restante do Estado. 0 interior possui 866 empresas com a certificação ISO 9001, já descontados a grande São Paulo e o litoral.

Pelo exposto, as questões de pesquisa que nortearam o desenvolvimento deste trabalho foram as seguintes: a certificação 1SO 9001 efetivamente gera na prática os benefícios elencados na literatura e fomenta a utilização de programas e ferramentas da qualidade nas empresas do interior do Estado de São Paulo? Trata-se de instrumentos fundamentais para a competitividade ou ainda trata-se de uma perspectiva para o futuro?

0 objetivo deste artigo é apresentar o resultado de uma pesquisa tipo surveyem que se verificaram e analisaram as principais características do processo de certificação 1SO 9001, seus benefícios, suas dificuldades e quais programas e ferramentas da qualidade são utilizados em empresas do interior do Estado de São Paulo.

De forma a garantir sua exequibilidade e foco, este estudo foi delimitado em relação a sua abrangência geográfica (interior do Estado de São Paulo), em relação a uma determinada característica organizacional (empresas certificadas ISO 9001) e em relação ao escopo de trabalho (sistemas de gestão da qualidade e programas e ferramentas da qualidade).

Na sequência desta introdução é apresentado um breve referencial teórico sobre gestão da qualidade, ISO 9001 e programas e ferramentas da qualidade. Após isso são mostrados e analisados os principais resultados obtidos na pesquisa e, por fim, apresentadas a conclusão do artigo e as referências bibliográficas utilizadas.

\section{Gestão da qualidade}

Para Lakhal, Pasin e Limam (2006) e Battika (2003), o conceito de qualidade relaciona-se tanto a produtos como serviços e contempla elementos como satisfação do cliente, controle de processos, padronização, melhoria contínua, parcerias à jusante e à montante na cadeia com vistas a obter melhorias e benefícios conjuntos e racionalização de tempo e insumos. De forma geral, a gestão da qualidade melhora o desempenho organizacional e proporciona vantagem competitiva às organizações que a adotam.

Segundo Juran e Gryna (1991, p. 43),

[...] para a maioria dos clientes, qualidade relaciona-se às características do produto que atendem suas necessidades. Além disso, qualidade quer dizer ausência de falhas, bem como um bom serviço ao cliente [...]. Uma definição abrangente para isso é "adequação ao uso".

A gestão da qualidade tem como objetivos a padronização de processos e, por meio de planejamento, controle e aprimoramento, a garantia da qualidade de produtos e serviços. Segundo Srdoc, Sluga e Bratko (2005), Lagrosen (2007), Lagrosen e Lagrosen (2003), as empresas necessitam adotar um sistema que priorize a qualidade em suas decisões para que seja possível alcançar e manter a qualidade de seus processos, produtos e serviços.

Qualidade tem muitas definições, que podem variar de acordo com o contexto, e no caso do segmento empresarial pode ser denominada como a conformidade aos requisitos dos clientes, atendimento das necessidades dos stakeholders e prevenção e gerenciamento de não conformidades, incluindo as ações para suas correções (KANUNGO; 
BHATNAGAR, 2002; AHMED; HASSAN, 2003; BATTIKHA, 2003; LAGROSEN; LAGROSEN, 2003; GARRATT, 2007; ZU, 2009).

Os processos de melhoria contínua da qualidade são baseados no ciclo PDCA, ilustrado na Figura 1.

Segundo Poksinska, Eklund e Dahlgaard (2006) e Lagrosen, Backstron e Lagrosen (2007), vários estudos demonstram que os SGQs proporcionam significativos benefícios às empresas. Contudo, os autores também relatam a existência de recorrentes dificuldades. Dentre os benefícios, os que mais se destacam são a melhoria nos processos, produtos e serviços, aumento da satisfação dos clientes, melhoria da imagem da empresa, abertura de novos mercados e maior vantagem competitiva diante da concorrência. Já em relação às dificuldades observam-se as seguintes: resistência à mudança, dificuldade no entendimento e aceitação de determinados preceitos da qualidade, falta de comprometimento da média gerência e baixo envolvimento da alta direção, incluindo aporte pequeno de capital para as atividades associadas à qualidade.

\section{Sistemas de gestão da qualidade ISO 9001}

Segundo Churchman e Bertalanffy (1972 apud OLIVEIRA, 2005), os sistemas são constituídos de conjuntos de componentes que atuam juntos na execução do objeto global do todo. 0 enfoque sistêmico é um modo de pensar a respeito desses sistemas totais e seus componentes. A teoria geral dos sistemas dá ênfase à inter-relação e interdependência entre os componentes que formam um sistema, que é visto como uma totalidade integrada, sendo muito difícil estudar seus elementos isoladamente. A norma ISO 9001 é um sistema com objetivo específico de desenvolver princípios de gestão da qualidade nas organizações.

As normas da família $1 S 09000$ são gerenciadas mundialmente pela International Organization for Standardization, organismo sem fins lucrativos fundado em 1947, sediado em Genebra, Suíça, cujo principal objetivo é o desenvolvimento de normas técnicas e o incentivo à padronização visando facilitar as relações internacionais nos campos científico, intelectual, econômico e tecnológico (ARUMUGAM; 001; FONG, 2008; HEUVEL, 2005). No Brasil, ela é representada pelo Instituto Nacional de Metrologia, Normalização e Qualidade Industrial - INMETRO.

A série $1 S 09000$ é composta pelas normas ISO 9000 (sistema de gestão da qualidade

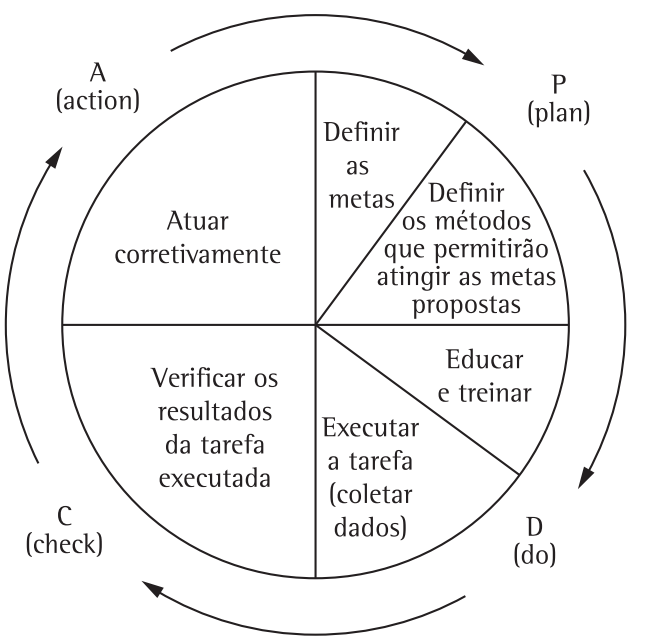

Figura 1. Ciclo PDCA. Fonte: adaptado de ISO 9001 (ASSOCIAÇÃO..., 2008).

- fundamentos e vocabulários), ISO 9001 (sistema de gestão da qualidade - requisitos) e 1S0 9004 (sistema de gestão da qualidade - diretrizes para melhoria de desempenho). A certificação é feita apenas com base na norma 1SO 9001, sendo as duas outras para orientação.

Para atingir a excelência organizacional, as mais recorrentes alternativas lançadas pelas organizações são o desenvolvimento e a implantação de sistemas de gestão da qualidade com base na norma ISO 9001 (ZENG; TIAN; SHI, 2005). Para que esse sistema promova o desempenho esperado, além das mudanças internas, é necessário que os stakeholders compartilhem de seus propósitos em relação à qualidade, apoiando, dentro do possível, a empreitada.

São indispensáveis o comprometimento e a ativa participação da alta direção, conforme preconiza a própria norma, nos processos de desenvolvimento e implantação do sistema, uma vez que recursos (financeiros, humanos e de infraestrutura) deverão ser disponibilizados em intensidades e momentos bastante específicos (HEUVEL, 2005). Ainda segundo o autor, alguns princípios preconizados pela $1 S 09001$ são:

- Foco no cliente;

- Liderança;

- Envolvimento de pessoas;

- Abordagem de processo;

- Abordagem sistêmica;

- Melhoria contínua;

- Abordagem factual para as tomadas de decisão; e 
- Parceria com os fornecedores.

A primeira versão da norma 1S0 9001 é de 1987; após isso houve mais duas revisões, em 1994 e 2000 (ARUMUGAM; 001; FONG, 2008). Em 2008 foi lançada uma emenda e não uma revisão completa. Nenhum requisito foi adicionado, mas alguns foram sutilmente melhorados. Algumas dessas pequenas mudanças foram feitas com o intuito de melhorar a interface com a ISO 14001:2004 - sistema de gestão ambiental (GALBINSKI, 2008; ASSOCIAÇÃO..., 2008). A macroestrutura da norma $1 S 09001$ é apresentada no Quadro 1.

Um SGQ baseado na norma ISO 9001 traz diversos benefícios às organizações, dos quais se destacam: aumento da eficiência operacional, maior conformidade de produtos e serviços a partir da redução de falhas e diminuição da variabilidade nos processos, atendimento dos requisitos do cliente com aumento de sua satisfação, diminuição de custos com retrabalhos e perdas, aumento das vantagens competitivas e melhoria da imagem da empresa (GUPTA, 2000; ROMANO, 2000; OZGUR; MEEK; TOKER, 2002; LAGROSEN; LAGROSEN, 2003; LAGROSEN, 2007; CLAVER; TARI, 2008; DICK; HERAS; CASADESÚS, 2008).

A despeito de todas as críticas sobre causar engessamento de processos e aumento do número de documentos, o SGQ com base na norma ISO 9001 induz à melhoria contínua em projetos, processos, produtos e serviços nas empresas que o adotam. Verifica-se, quando bem implantado e gerenciado, a racionalização no uso de insumos, maior controle de processos com consequente redução do desperdício e conscientização maior da mão de obra em relação à importância do seu trabalho (BHUYIAN; BAGHEL, 2005).

\section{Programas e ferramentas da qualidade}

Utilizados para desenvolver, implementar, monitorar e melhorar os preceitos da qualidade nas organizações, os programas e ferramentas da qualidade representam importantes e necessários instrumentos para que os SGQs obtenham máxima eficiência e eficácia (BAMFORD; GREATBANKS, 2005; ALSALEH, 2007). Avaliar a satisfação do cliente, visando a melhoria da qualidade nos serviços e produtos, é uma das importantes funções competitivas dos programas e ferramentas da qualidade. Essa prática promove a confiabilidade e produz consideráveis vantagens à empresa em relação aos seus concorrentes (CARNEVALLI; MIGUEL; CALARGE, 2008).
Quadro 1. Estrutura da norma ISO 9001.

\begin{tabular}{|l|}
\hline \multicolumn{1}{|c|}{ Macro-itens da norma ISO 9001} \\
\hline 0 - Introdução \\
\hline 1 - Objetivo \\
\hline 2 - Referência normativa \\
\hline 3 - Termos e definições \\
\hline 4 - Sistema de gestão da qualidade \\
\hline 5 - Responsabilidade da administração \\
\hline 6 - Gestão de recursos \\
\hline 7 - Realização do produto \\
\hline 8 - Medição, análise e melhoria \\
Fonte: 1 SO 9001 (AsSOCıAç̃̃o..., 2008).
\end{tabular}

Para Thia et al. (2005), as ferramentas da qualidade têm sido desenvolvidas e aprimoradas para sustentar a aplicação e utilização da gestão da qualidade nas empresas; dessa forma, considera-se que elas são imprescindíveis para o SGQ obter o sucesso largamente anunciado na literatura científica.

Os programas e ferramentas da qualidade mais comumente utilizados pelas empresas, segundo Khanna, Laroiya e Sharma (2010), estão apresentados no Quadro 2. Vale destacar que alguns deles, como benchmarking, brainstorming e fluxograma, são instrumentos utilizados também em diversas outras áreas da gestão além da qualidade.

\section{Método de pesquisa}

Para a realização da presente pesquisa utilizou-se o método survey. Primeiramente foi feita a definição/delimitação do tema, a questão de pesquisa foi estabelecida e definido seu objetivo. Após isso, realizou-se uma revisão teórica, quando então foi elaborado o instrumento de coleta de dados (questionário), que foi testado com uma empresa da amostra. Na sequência, o questionário ajustado foi enviado para todas as empresas da amostra (empresas certificadas segundo a norma ISO 9001 do interior do Estado de São Paulo). Houve o recebimento das respostas e os dados foram tabulados, tratados e analisados. Por fim, elaborou-se a conclusão do trabalho.

0 questionário foi preparado seguindo as recomendações da literatura científica: deve ser objetivo, não ser muito extenso e deve contemplar elementos que permitam responder à questão de pesquisa estabelecida e o alcance do objetivo proposto (KANUNGO; BHATNAGAR, 2002; MADY, 2009). Ele foi estruturado em três seções principais: caracterização da empresa, bloco de questões relativas ao SGQ e bloco de questões relacionadas aos programas e ferramentas da qualidade. 
Quadro 2. Exemplos e definições dos principais programas e ferramentas da qualidade.

Programas e ferramentas da qualidade

\begin{tabular}{|c|c|}
\hline $5 S$ & $\begin{array}{l}\text { Seiri, Seiton, Seiso, Seiketsu e Shitsuke, de origem japonesa ou em português Descarte, Arrumação, } \\
\text { Limpeza, Saúde e Disciplina. Tem como objetivos a diminuição de desperdícios e custos e aumento da } \\
\text { produtividade baseado na melhoria da qualidade de vida dos funcionários e modificações no ambiente } \\
\text { de trabalho (KHANA, 2009). }\end{array}$ \\
\hline $5 \mathrm{~W} 1 \mathrm{H}$ ou $5 \mathrm{~W} 2 \mathrm{H}$ & $\begin{array}{l}\text { Trata-se de uma ferramenta que auxilia na estruturação de planos de ação a partir de questões-chave } \\
\text { (0 quê? Quem? Quando? Onde? Por quê? e Como?). Já a 5W2H acrescenta a questão "Quanto?", } \\
\text { enfatizando o custo da ação (LIN; LUH, 2009). }\end{array}$ \\
\hline $\begin{array}{l}\text { Análise do modo e do } \\
\text { efeito das falhas (FMEA) }\end{array}$ & $\begin{array}{l}\text { É um processo sistemático e documentado para avaliação e redução de riscos de falhas em projetos } \\
\text { e processos. Seu objetivo é identificar, definir, priorizar e reduzir os potenciais de falhas o mais } \\
\text { cedo possivel, diminuindo as chances de sua ocorrência tanto nos clientes internos como externos } \\
\text { (LAGROSEN; LAGROSEN, 2005; BAMFORD; GREATBANKS, 2005; JOHANSSON et al., 2006). }\end{array}$ \\
\hline Benhchmarking & $\begin{array}{l}\text { É um processo contínuo e sistemático para avaliar produtos, serviços e processos em organizações que } \\
\text { são reconhecidas como possuidoras das melhores práticas, com a finalidade de servir de referência para } \\
\text { organizações menos avançadas (ROBSON; MITCHELL, 2007; KHANNA, 2009). }\end{array}$ \\
\hline Brainstorming & $\begin{array}{l}\text { É um processo de grupo em que os indivíduos emitem ideias de forma livre, em grande quantidade, } \\
\text { sem críticas e no menor espaço de tempo possivel (KHANNA, 2009; BAMFORD; GREATBANKS, 2005). }\end{array}$ \\
\hline Check list & $\begin{array}{l}\text { É utilizado para colher dados baseados em observações amostrais com o objetivo de verificar com } \\
\text { que frequência ocorre um evento ao longo de um período de tempo determinado (GARRATT, 2007; } \\
\text { VENKATRAMAN, 2007). }\end{array}$ \\
\hline $\begin{array}{l}\text { Controle estatístico do } \\
\text { processo (CEP) }\end{array}$ & $\begin{array}{l}\text { Controla a variação da média e desvio padrão de uma determinada grandeza utilizando as cartas de } \\
\text { controle. Objetiva manter os processos dentro dos limites estabelecidos (LAGROSEN; LAGROSEN, 2005; } \\
\text { CHILESHE, 2007). }\end{array}$ \\
\hline $\begin{array}{l}\text { Desdobramento da função } \\
\text { da qualidade (QFD) }\end{array}$ & $\begin{array}{l}\text { Tem por objetivo auxiliar o time de desenvolvimento a incorporar no projeto as reais necessidades } \\
\text { dos clientes. Por meio de um conjunto de matrizes parte-se dos requisitos expostos pelos clientes e } \\
\text { realiza-se um processo de "desdobramento" transformando-os em especificações técnicas do produto } \\
\text { (LAGROSEN; LAGROSEN, 2005; AHMED; HASSAN, 2003; JOHANSSON et al., 2006). }\end{array}$ \\
\hline Diagrama de lshikawa & $\begin{array}{l}\text { É uma representação gráfica que permite a organização de informações por semelhança a partir de seis } \\
\text { eixos principais (método, material, máquinas, meio ambiente, mão de obra e medição), possibilitando } \\
\text { a identificação das possiveis causas de um determinado problema, ou efeito, de forma específica e } \\
\text { direcionada (IVANOVIC; MAJSTOROVIC, 2006; VENKATRAMAN, 2007). }\end{array}$ \\
\hline Fluxograma & $\begin{array}{l}\text { Representa a sequência de atividades e processos, demonstra o fluxo dessas ações e permite a } \\
\text { identificação de problemas e qual a sua origem (LAGROSEN; LAGROSEN, 2005; AHMED; HASSAN, } \\
\text { 2003; JOHANSSON et al., 2006). }\end{array}$ \\
\hline Gráfico de Pareto & $\begin{array}{l}\text { Ferramenta gráfica e estatística que organiza e identifica os dados de acordo com suas prioridades, como } \\
\text { por exemplo pela decrescente ordem de frequência (CHILESHE, 2007; HAGEMEYER; GERSHENSON; } \\
\text { JOHNSON, 2006). }\end{array}$ \\
\hline Histograma & $\begin{array}{l}0 \text { histograma é uma ferramenta estatística que, em forma de gráfico de barras, ilustra a distribuição de } \\
\text { frequência (LAGROSEN; LAGROSEN, 2005; HAGEMEYER; GERSHENSON; JOHNSON, 2006). }\end{array}$ \\
\hline Poka yoke & $\begin{array}{l}\text { Objetiva a minimização de erros por meio de sistematização de mecanismos simples de prevenção. Tem } \\
\text { o significado "à prova de erros" em português (FISHER, 1999; DAS et al., 2008). }\end{array}$ \\
\hline Servqual & $\begin{array}{l}\text { Questionário composto por } 22 \text { perguntas que pretendem medir o desempenho da organização em } \\
5 \text { dimensões (tangibilidade, confiabilidade/credibilidade, receptividade, garantia e empatia), em dois } \\
\text { eixos principais: percepção e expectativa. É no gap entre esses dois elementos que deve se centrar a } \\
\text { atenção dos gestores (DONNELLY et al., 2006; LADHARl, 2009; SIGALA, 2004; UENO, 2008). }\end{array}$ \\
\hline Setup rápido & $\begin{array}{l}\text { É utilizado para reduzir o tempo de troca de ferramentas. Objetiva eliminar os setups ou, em último caso, } \\
\text { mudar os setups internos para externos (CHILESHE, 2007; HAGEMEYER; GERSHENSON; JOHNSON, 2006). }\end{array}$ \\
\hline Seis sigma & $\begin{array}{l}0 \text { seis sigma pode ser entendido como uma metodologia utilizada para reduzir continuamente a } \\
\text { variabilidade dos processos e produtos, considerando a situação atual e a meta especificada, } \\
\text { normalmente pelos clientes. Um processo Seis sigma é aquele no qual é rara a presença de uma } \\
\text { variação fora das especificações (LAGROSEN; LAGROSEN, 2005; AHMED; HASSAN, 2003). }\end{array}$ \\
\hline Times da qualidade & $\begin{array}{l}\text { Também conhecidos como círculos de controle da qualidade, são pequenos grupos de colaboradores, } \\
\text { em geral de } 5 \text { a } 10 \text { profissionais, que se reúnem voluntariamente e de forma regular para monitorar, } \\
\text { identificar, analisar e propor soluções para os problemas organizacionais (denominados de projetos), } \\
\text { principalmente aqueles relacionados à produção (LYU JUNIOR; CHANG; CHEN, 2009). }\end{array}$ \\
\hline
\end{tabular}

Com o teste-piloto do questionário foi possivel identificar alguns pontos de melhoria do instrumento, que se concentraram mais na melhoria da redação e fusão de algumas poucas questões muito semelhantes. 0 questionário final foi enviado, via e-mail, para os "responsáveis da direção" (RDs) pelos SGQs das empresas constantes da amostra pretendida.

Cada questão do questionário, excetuando aquelas referentes à primeira seção (caracterização da empresa), continha uma afirmativa com 5 alternativas baseadas na escala Likert para verificar 
o grau de concordância dos respondentes em relação a ela, que eram: a) discordo completamente; b) discordo parcialmente; c) não concordo e nem discordo; d) concordo parcialmente; e e) concordo completamente. Para permitir a tabulação e análise dos dados, a estas alternativas foram associados escores que variaram de 1,0 a 5,0, sendo 1,0 para a alternativa discordo completamente e 5,0 para a concordo completamente. Logo, respostas com valores situados entre 1,0 e 3,0 discordam da afirmativa posta, respostas com valor 3,0 não concordam nem discordam da afirmativa e valores acima de 3,0 concordam com a afirmativa.

As respostas foram tabuladas, tratadas e analisadas com o auxílio do software Statistica. Fez-se uma análise em relação às médias de cada uma delas e depois foi feita uma análise da correlação estatística entre elas. Para verificação de relações entre variáveis (escopo da certificação $x$ benefícios auferidos) foi utilizado 0 teste qui-quadrado e para comparação das dificuldades entre grupos independentes com base no porte das empresas aplicou-se o teste não paramétrico de Kruskal-Wallis. 0 nível de significância adotado para ambos os testes foi de $5 \%$.

0 questionário (Anexo 1) foi enviado a 866 organizações do interior do Estado de São Paulo que, conforme o Instituto Nacional de Metrologia, Normalização e Qualidade Industrial - INMETRO (INSTITUTO..., 2009b), possuíam a certificação ISO 9001 em 2009. Obteve-se um retorno de 236 delas, o que corresponde a uma taxa de resposta de $27,25 \%$. Na Figura 2 pode-se verificar o fluxo metodológico de desenvolvimento da pesquisa.

\section{Apresentação e análise dos resultados}

Nesta seção do texto será caracterizado o grupo de empresas participantes da pesquisa e apresentados e analisados os principais dados obtidos com a aplicação do questionário.

0 Quadro 3 apresenta o porte das empresas respondentes.

0 Quadro 3 ilustra que a maioria das organizações estudadas é de grande porte. Aqui já se caracteriza uma limitação do estudo, pois as conclusões a que se chegarem deverão estar restritas, além do recorte geográfico (interior de São Paulo), ao porte das empresas (principalmente grandes).

A Figura 3 apresenta a distribuição dos ramos de atividade das empresas estudadas por meio do seu percentual dentro do conjunto. Os números dentro dos parênteses significam a quantidade absoluta de empresas naquela determinada categoria.

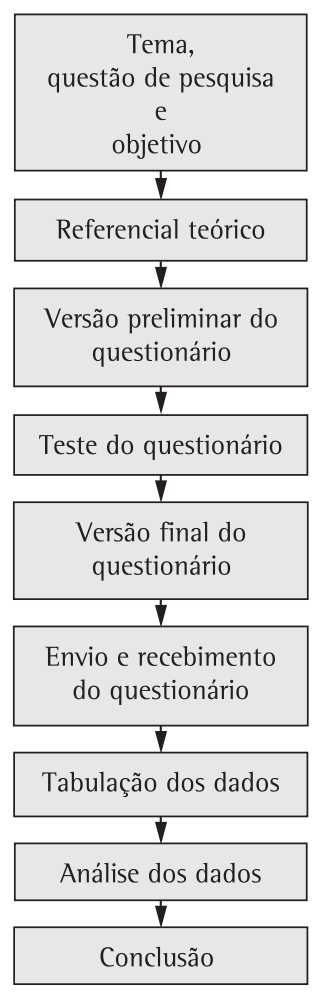

Figura 2. Fluxo metodológico do desenvolvimento da pesquisa.

Quadro 3. Porte das empresas respondentes.

\begin{tabular}{|c|r|}
\hline Porte & \multicolumn{1}{|c|}{ Frequência (\%) } \\
\hline Pequeno & 37 empresas - 15,67 \\
\hline Médio & 63 empresas - 26,70 \\
\hline Grande & 136 empresas - 57,63 \\
\hline
\end{tabular}

Pelo exposto na Figura 3, o setor de usinagem apresenta o maior número de empresas estudadas, seguidos pelos setores automotivo, gráfico, eletrônico, bebidas e construção. Apesar de a amostra estudada incluir empresas de serviço, a participação destas nesta pesquisa foi baixa. Essa tendência ratifica a diferença do número de certificações ISO 9001 entre empresas de serviços e de manufatura no Brasil, em que esta última supera em larga escala a primeira (INSTITUT0..., 2009b).

A Figura 4 apresenta a duração dos processos de implantação dos SGQs até a certificação ISO 9001.

Pode-se verificar na Figura 4 que a maioria das empresas estudadas levou até 12 meses para obter a certificação ISO 9001. Esse fato pode ser explicado pela maioria delas utilizar o auxílio de consultorias especializadas, conforme será mostrado na Figura 6, para o desenvolvimento e implantação desse tipo de sistema. Essas empresas de consultoria costumam 


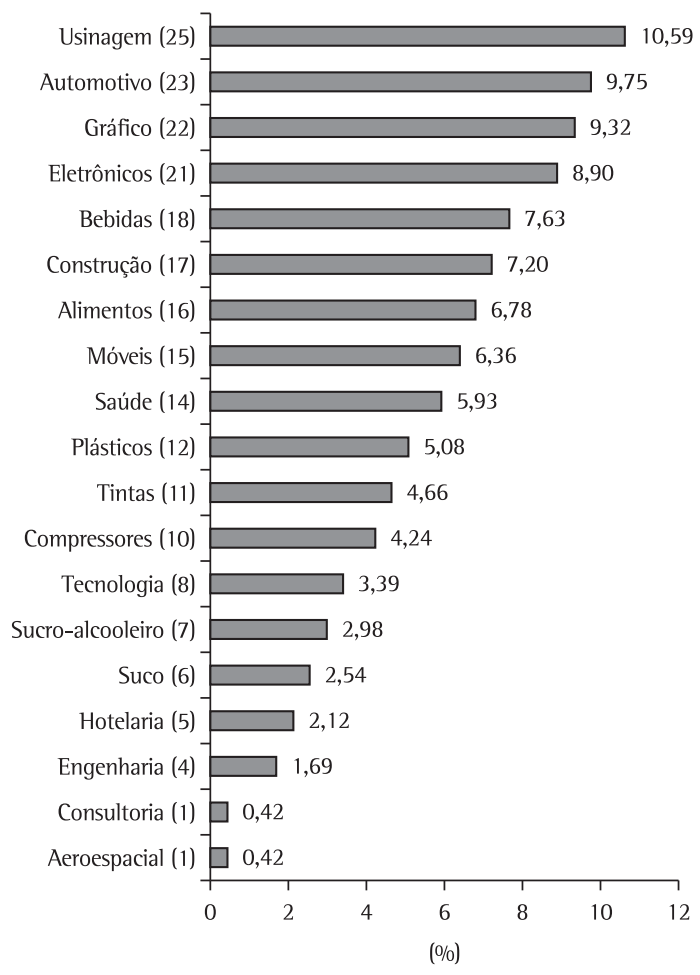

Figura 3. Distribuição dos ramos de atividades das empresas.

ter procedimentos com padrões preestabelecidos e bastante rígidos para implantação dos sistemas ISO 9001 e, por esse motivo, os prazos para o seu desenvolvimento e implantação ficam muito próximos independentemente do ramo ou tipo de empresa.

Essa questão do padrão próprio único e rígido dos mecanismos de desenvolvimento e implantação dos sistemas de gestão da qualidade com base na ISO 9001 por parte das empresas de consultoria pode ser considerada uma dificuldade na implantação desse tipo de sistema. Acredita-se que essa situação cerceia uma das maiores contribuições que o processo de desenvolvimento desse sistema poderia proporcionar: crescimento e melhoria com base na autorreflexão sobre o planejamento, controle e desempenho organizacional.

A Figura 5 apresenta a distribuição das empresas estudadas pelo ano em que se certificaram segundo a norma $1 S 0$ 9001. Os números dentro dos parênteses significam a quantidade absoluta de empresas naquela determinada categoria.

$\mathrm{Na}$ Figura 5 observam-se picos de certificações nas empresas estudadas em 1997, 2003, 2004 e 2006. O pico de 1997 possivelmente está relacionado com o transcorrer de um prazo significativo ( 3 anos) após o lançamento da norma

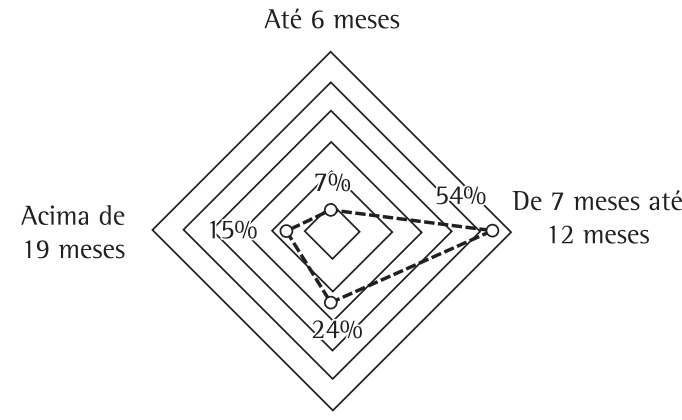

De 13 meses até

18 meses

Figura 4. Tempo de certificação ISO 9001.

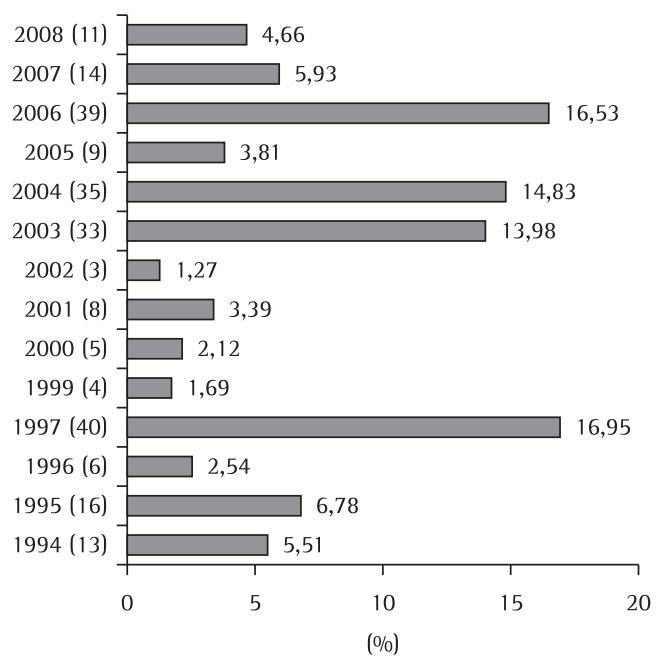

Figura 5. Ano de certificação 1509001.

ISO 9001 versão 1994, o que permitiu que as empresas conhecessem o sistema, decidissem por adotá-lo e o desenvolvessem.

Os picos de 2003 e 2004 devem estar relacionados a motivos semelhantes aos de 1994, mas agora voltados para a versão de 2000 da norma, e o pico de 2006 pode estar atrelado ao fato de que as empresas possuíam fôlego financeiro para investir em melhorias técnicas e de gestão em função do considerável desenvolvimento econômico verificado no período, quando o desenvolvimento desse tipo de sistema tratava-se de uma boa alternativa já naquela época.

A Figura 6 apresenta três importantes informações sobre os SGQs das empresas participantes da pesquisa: se utilizam times da qualidade para apoiar o desenvolvimento das atividades relacionadas ao SGQ, o escopo da certificação (empresa toda ou parte dela) e recebimento de auxílio de empresa especializada para implantação do sistema. 
Verifica-se que quase a totalidade das empresas estudadas utiliza os times da qualidade como forma de dar suporte ao desenvolvimento da qualidade. Isso significa um efetivo e interessante investimento na melhoria contínua a partir de recursos humanos próprios.

Já em relação ao escopo da certificação, percebe-se um relativo equilíbrio entre a certificação de toda empresa ou de parte dela. A escolha pelo escopo parcial, em geral, acontece quando as empresas optam por certificar suas atividades mais importantes e que mais impactam seus resultados totais ou quando estão iniciando no campo da qualidade e querem realizar uma primeira experiência para amadurecimento sem comprometer muitos recursos.

Verifica-se também que a maioria delas utilizou consultoria externa para obter a certificação. Apesar da crítica feita anteriormente neste texto às empresas de consultoria em relação à excessiva padronização do processo e dos instrumentos de implantação dos SGQs 150 9001, seu suporte e expertise são interessantes e importantes elementos para viabilizar, otimizar e reduzir o tempo de desenvolvimento e implantação desse tipo de sistema nas empresas em geral.
Os dados apresentados a seguir estão dispostos em ordem decrescente de média, de forma a permitir melhor visualização e interpretação dos resultados. Isso significa que as questões originalmente não tinham esta sequência no questionário e que foram renumeradas para apresentação segundo esse critério.

A Figura 7 apresenta a sequência de escores obtidos para as questões relativas aos benefícios auferidos com a implantação do sistema ISO 9001.

A questão 1, "Aumento da satisfação dos clientes", obteve o maior escore $(4,11)$ dentre os benefícios apresentados aos respondentes e foi a única que ficou com média superior a 4,0. Esse fato corrobora o principal objetivo da norma, destacado na própria teoria da qualidade, que é o aumento da satisfação dos clientes, que pode ser conseguido por meio do controle e melhoria contínua de processos, produtos e serviços. 0 bom desempenho nesse item aumenta consideravelmente as chances de maior retorno financeiro e de aumento da longevidade das organizações.

As próximas cinco questões (Q2, Q3, Q4, Q5 e Q6) apresentaram escores também significativos (média acima de 3,5), confirmando que a certificação 1509001 também proporciona
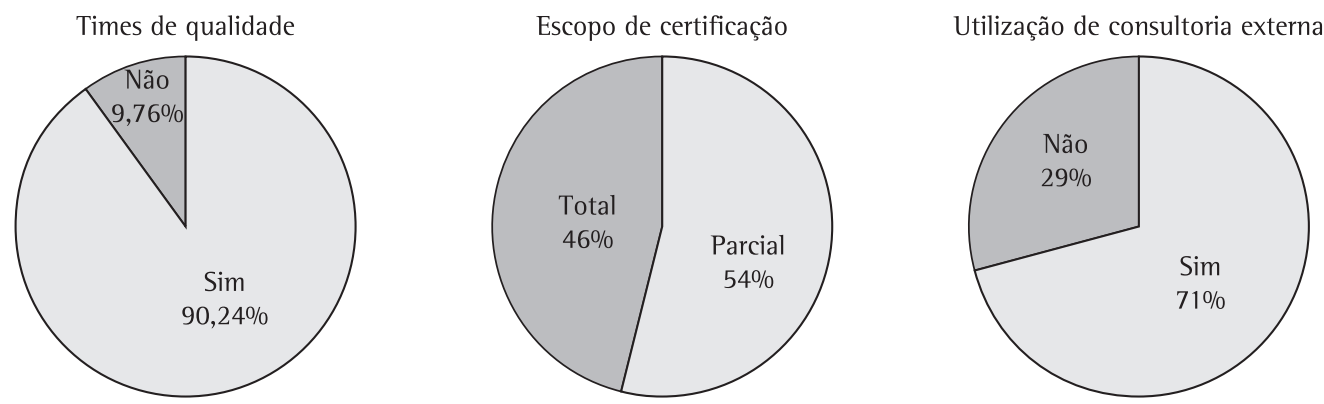

Figura 6. Características gerais dos SGQs estudados.

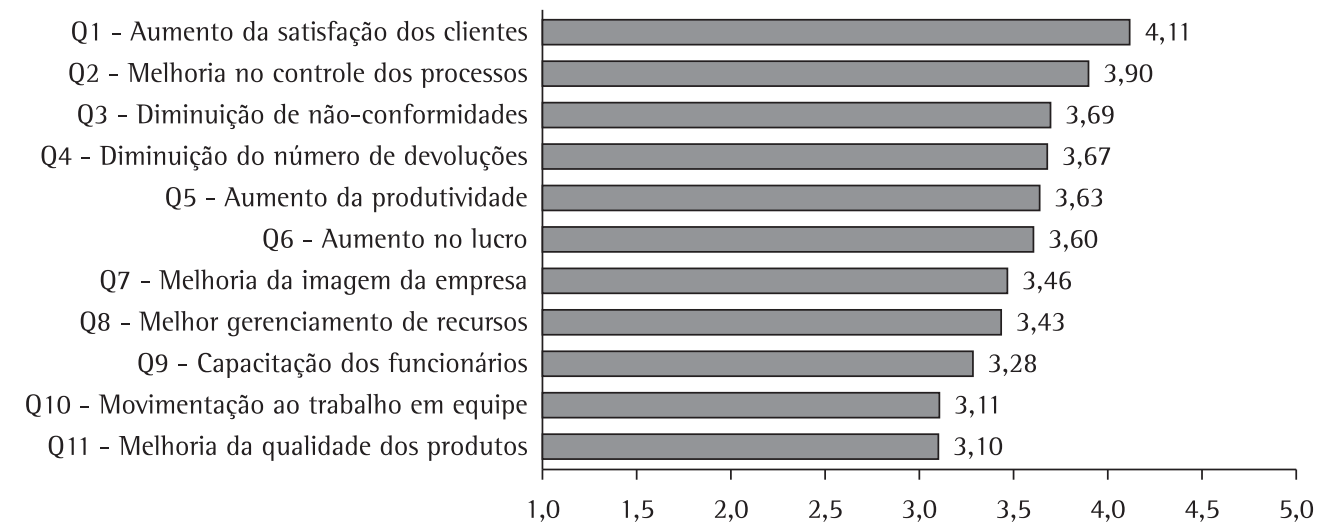

Figura 7. Benefícios auferidos com a certificação 1SO 9001. 
melhoria no controle dos processos, diminuição de não conformidades e do número de devoluções, aumento da produtividade e do lucro.

Todos os demais benefícios provenientes da implantação de um SGQ certificado segundo a norma ISO 9001 contidos nas questões de Q7 a Q11 também foram confirmados, porém com menor intensidade que os anteriores. São eles: melhoria da imagem da empresa, melhoria no gerenciamento dos recursos, capacitação de funcionários, motivação ao trabalho em equipe e melhoria na qualidade dos produtos.

As principais dificuldades enfrentadas pelas organizações pesquisadas para obter a certificação ISO 9001 são apresentadas na Figura 8.

Pode-se observar que a resistência dos funcionários, existência de não conformidades, ausência de indicadores de processo e excessiva burocracia gerada pela 150 9001, relativas às questões Q12, Q13, Q14 e Q15, foram classificadas pelos respondentes com um escore muito próximo de 3,0, o que significa que não são dificuldades nem benefícios do ponto de vista deles. Isso de certa forma contraria o que é largamente preconizado na literatura científica, mas talvez 0 alto índice de utilização de empresas de consultoria para auxiliar no processo de desenvolvimento e implantação desses sistemas tenha colaborado com o estabelecimento de procedimentos visando prevenir a ocorrência desses problemas.

Já a questão 16, que afirmava que o baixo envolvimento da alta direção era uma dificuldade para implantação do sistema, apresentou um escore abaixo de 3,0, caracterizando que os respondentes discordam consideravelmente dela. Com o amadurecimento e a maior divulgação dos resultados bem-sucedidos desses sistemas por empresas de todo mundo, os empresários começam a implantá-los efetivamente acreditando nos benefícios operacionais que eles podem proporcionar e não só como um mecanismo de marketing.

A pesquisa também verificou quais os principais programas e ferramentas da qualidade são utilizados pelas empresas estudadas (Figura 9).

Pode-se classificar os programas e ferramentas da qualidade segundo sua utilização pelas empresas participantes em três grupos: os mais utilizados (diagrama de lshikawa, programa 5S, PDCA, brainstorming e gráfico de Pareto), os medianamente utilizados (CEP, 5W1H, check list, FMEA, histograma e benchmarking) e os menos utilizados (seis sigma, servqual, QFD, setup rápido e poka yoke).

Os instrumentos mais utilizados são, em grande medida, os mais simples e considerados estruturantes, ou seja, aqueles que vão criar o "alicerce" para a evolução do SGQ e para a adoção de programas e ferramentas mais complexos.

Alguns dos instrumentos classificados no grupo dos medianamente utilizados causam certa estranheza, pois, segundo a literatura científica e seu baixo grau de complexidade, poderiam estar tranquilamente no grupo dos mais utilizados. São eles: $5 \mathrm{~W} 1 \mathrm{H}$, check list, histograma e benchmarking. Talvez os respondentes utilizem alguma forma adaptada deles ou mesmo não conheçam a nomenclatura utilizada nesta pesquisa. Mas o fato é que não é possível afirmar isso com as informações disponíveis.

0 terceiro grupo é nitidamente composto por elementos com maior grau de complexidade e que exige maior maturidade em termos de gestão das organizações para os utilizarem, apesar do alto retorno em termos de resultado que podem gerar.

Por fim, procurou-se identificar quais os principais benefícios, de uma forma geral, auferidos com a utilização dos programas e ferramentas da qualidade pelas empresas estudadas (Figura 10).

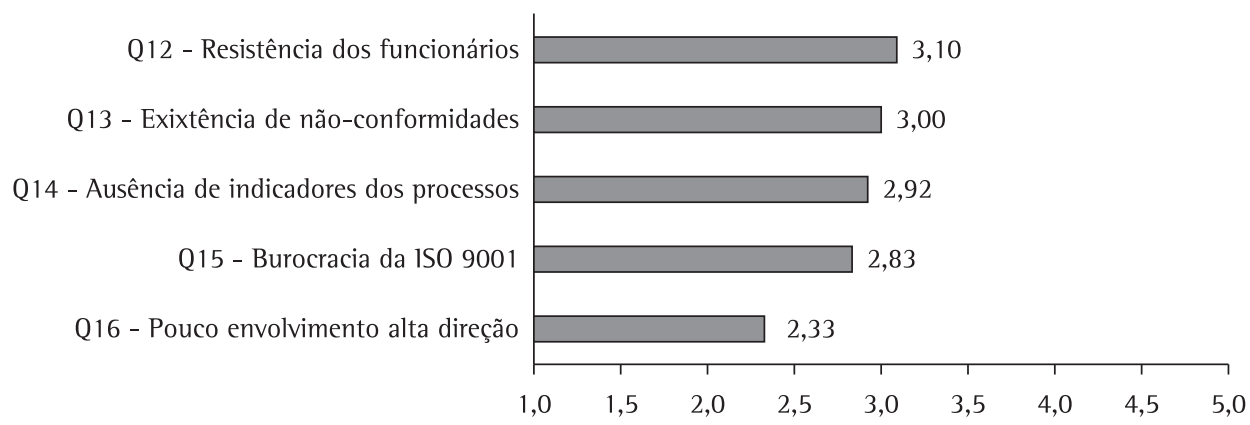

Figura 8. Dificuldades no processo de certificação ISO 9001. 
Observa-se que os programas e ferramentas da qualidade efetivamente proporcionam os benefícios apontados na literatura, ainda que com intensidades variadas. Os benefícios com maior escore (acima de 4,0) foram o "Aumento da satisfação do cliente”, que se coadunou com o principal benefício, já relatado neste texto, obtido com a adoção dos sistemas ISO 9001 e a "Melhoria na gestão de recursos".

Os demais benefícios também se confirmaram (medição e monitoramento de desempenho, identificação e solução de problemas, aumento da

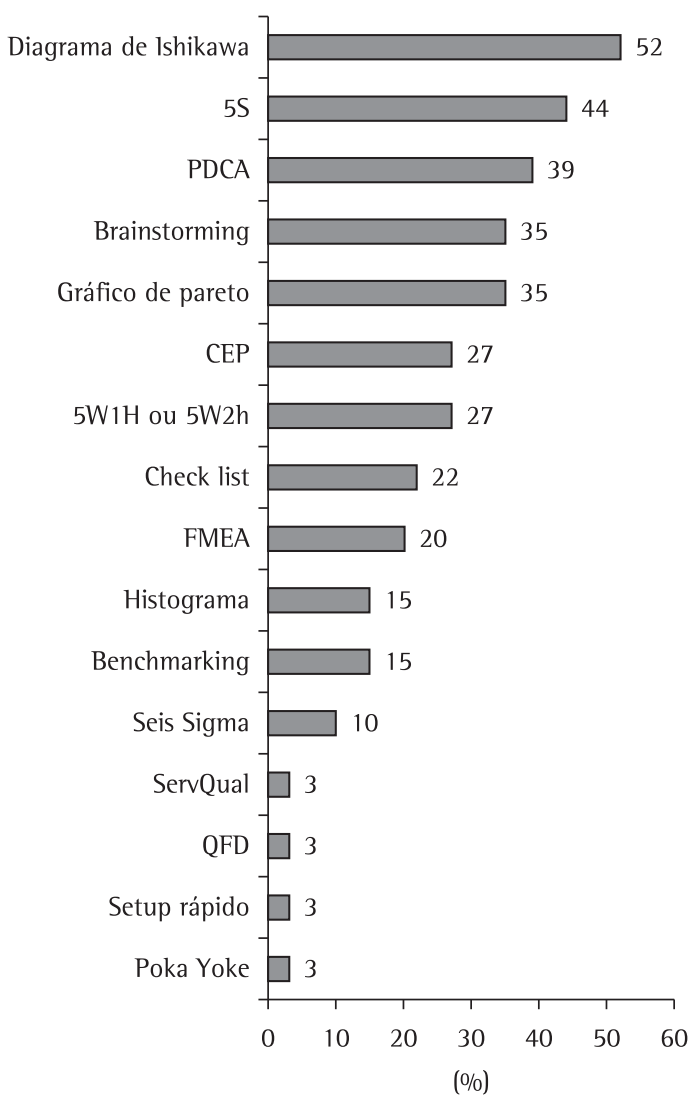

Figura 9. Utilização de ferramentas da qualidade. produtividade e melhoria no ambiente de trabalho), porém com um escore um pouco mais baixo (inferior a 4,0).

A resistência dos funcionários para a utilização das ferramentas da qualidade foi a única dificuldade apurada e apresentou um escore de 2,84, o que indica que não apresenta uma relevância significativa, porém ainda pode ser considerada um desafio para as organizações capacitarem seus funcionários quanto ao uso de instrumentos importantes para a qualidade.

A Tabela 1 fornece informações sobre a correlação estatística entre as questões ao nível de 5\%. Os números em destaque (sublinhados e em negrito) são valores com nível de correlação significativo, ou seja, acima de 0,50 , que serão brevemente discutidos na sequência.

As questões 1 e 17 (aumento da satisfação dos clientes pela certificação ISO 9001 e aumento da satisfação dos clientes pela utilização de ferramentas da qualidade) apresentaram correlação de 0,71. Essa correlação já era esperada, já que os programas e ferramentas da qualidade são os principais instrumentos pelos quais os sistemas ISO 9001 conseguem gerar maior satisfação dos clientes.

A correlação entre as questões 3 e 4 (diminuição de não conformidades e diminuição de devoluções), com valor de 0,50, também é evidente, já que com a redução dos erros no processo de produção os produtos tendem a não ser devolvidos por defeitos durante seu uso.

A correlação entre as questões 3 e 6 (diminuição de não conformidades e aumento do lucro) obteve um valor de 0,60 , o que quer dizer que a prevenção de defeitos e problemas proporciona redução no retrabalho e, conforme discutido no parágrafo anterior, também diminui a devolução de produtos, gerando, portanto, aumento da lucratividade.

As questões 5 e 6 (aumento da produtividade e aumento do lucro) obtiveram um coeficiente 0,57 em sua correlação. Isso também já era esperado, pois aumentando-se a produtividade, ou seja,

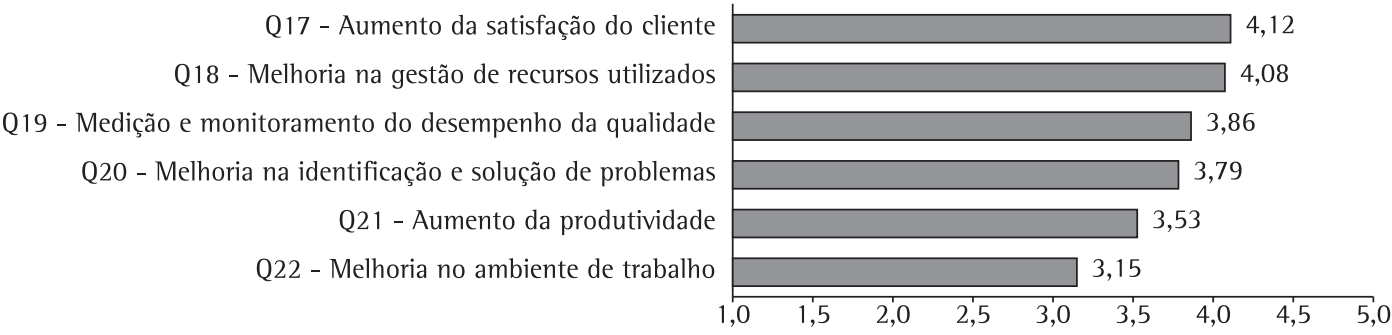

Figura 10. Benefícios auferidos com a utilização dos programas e ferramentas da qualidade. 
Tabela 1. Correlação estatística entre as questões.

\begin{tabular}{|c|c|c|c|c|c|c|c|c|c|c|c|c|c|c|c|c|c|c|c|c|c|c|}
\hline & Q1 & 2 & Q3 & Q4 & Q5 & Q6 & Q7 & 8 & Q9 & Q10 & Q11 & Q12 & Q13 & Q14 & Q15 & Q16 & Q17 & 18 & 19 & Q20 & Q21 & Q22 \\
\hline Q2 & 0,12 & 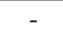 & - & - & - & - & - & - & - & - & - & 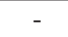 & & & & & & 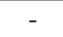 & - & & 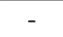 & - \\
\hline Q3 & 27 & & - & - & - & - & _. & - & - & - & - & - & - & _. & - & - & - & - & - & - & - & - \\
\hline Q4 & 22 & 13 & $\underline{0,50}$ & - & - & - & - & - & - & - & - & . & - & - & - & . & . & . & . & - & - & - \\
\hline Q5 & 23 & $-0,16$ & 41 & 0 , & 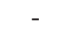 & - & - & - & - & - & - & - & - & - & - & - & 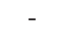 & 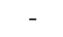 & 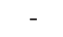 & 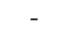 & 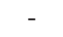 & . \\
\hline Q6 & 15 & $-0,33$ & 60 & 43 & $\underline{0,57}$ & - & - & - & - & - & - & - & - & - & - & - & - & - & - & - & - & - \\
\hline Q7 & 05 & 4 & 17 & $-0,18$ & $-0,25$ & $-0,32$ & - & - & - & - & - & - & - & - & 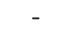 & 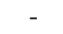 & - & - & - & - & - & - \\
\hline Q8 & 1,15 & & 37 & 0,35 & 0,51 & 0,55 & $-0,39$ & - & - & - & - & - & - & - & - & - & - & - & - & - & - & - \\
\hline Q9 & $-0,05$ & 17 & 0,05 & 5 & 0,12 & 0,12 & 0,04 & 0,05 & - & - & - & 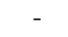 & - & - & 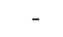 & 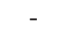 & - & - & - & - & - & - \\
\hline 10 & 22 & 23 & 04 & $-0,32$ & $-0,25$ & $-0,15$ & $-0,04$ & $-0,03$ & 0,0 & - & - & 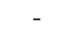 & 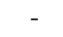 & - & 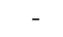 & - & 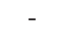 & - & - & - & - & - \\
\hline Q11 & 25 & 12 & 0,20 & 11 & 0,30 & 0,20 & 0,00 & 0,27 & $-0,14$ & $-0,07$ & 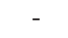 & 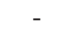 & - & - & _ & 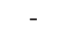 & - & - & - & - & - & - \\
\hline 212 & 28 & 04 & 16 & 23 & 0,39 & 0,11 & $-0,16$ & 0,01 & $-c$ & 0,01 & 0,26 & 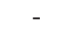 & - & - & - & - & 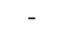 & 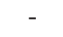 & 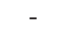 & . & - & - \\
\hline 213 & 0,07 & $-0,20$ & 0,26 & P & 0,06 & 0,23 & 0,06 & 0,11 & -0 & $-0,23$ & 0 & $-0,02$ & - & - & 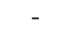 & 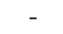 & - & - & - & - & - & - \\
\hline 214 & $-0,01$ & 0,18 & 0,16 & 0,04 & 0,00 & $-0,26$ & $-0,22$ & $-0,08$ & $-0,03$ & 0,12 & $-0,07$ & $-0,05$ & 0,01 & - & - & - & 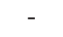 & 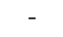 & 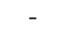 & - & - & - \\
\hline 215 & 0,12 & 0,23 & 0,12 & 0,02 & 0,12 & $-0,07$ & 0,08 & $-0,08$ & $-0,06$ & $-0,02$ & 0,21 & 0,07 & 0,27 & $\underline{0,53}$ & 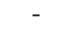 & - & - & - & - & - & - & - \\
\hline Q16 & $-0,04$ & 0,12 & $-0,03$ & $-0,10$ & $-0,24$ & $-0,14$ & $-0,12$ & 0,14 & $-0,11$ & 0,32 & $-0,01$ & $-0,10$ & $-0,10$ & 0,05 & $-0,16$ & - & - & - & - & - & - & - \\
\hline Q17 & $\underline{0,71}$ & 0,06 & 0,26 & $-0,08$ & 0,19 & 0,16 & $-0,14$ & 0,15 & & & & 0,23 & & 0,04 & 0,14 & & - & - & - & - & - & - \\
\hline Q18 & 0,14 & 0,24 & 0,44 & 0,02 & 0,28 & 0,18 & $-0,17$ & 0,37 & $-0,18$ & 0,00 & 0,45 & 0,20 & 0,12 & 0,25 & 0,47 & $-0,17$ & 0,22 & - & - & - & - & - \\
\hline Q19 & 0,32 & 0,12 & 0,46 & 0,35 & 0,04 & 0,29 & 0,00 & 0,16 & $-0,03$ & $-0,03$ & 0,28 & 0,22 & 0,10 & 0,17 & 0,07 & 0,09 & 0,05 & 0,31 & - & - & - & - \\
\hline Q20 & $-0,01$ & $-0,24$ & 0,30 & 0,21 & 0,12 & 0,16 & 0,00 & $-0,13$ & 0,25 & $-0,19$ & 0,04 & $-0,10$ & $-0,06$ & 0,18 & 0,18 & $-0,03$ & $-0,19$ & 0,03 & 0,38 & - & - & - \\
\hline Q21 & 0,26 & 0,14 & 0,39 & 0,03 & 0,24 & 0,22 & $-0,03$ & 0,34 & $-0,20$ & 0,11 & $\underline{0,51}$ & 0,10 & 0,19 & 0,15 & 0,36 & $-0,19$ & 0,38 & $\underline{0,80}$ & 0,27 & $-0,07$ & - & - \\
\hline Q22 & 0,10 & 0,18 & $-0,03$ & 0,00 & $-0,16$ & $-0,09$ & $-0,07$ & $-0,15$ & 0,01 & 0,00 & 0,26 & $-0,05$ & 0,10 & 0,12 & 0,15 & $-0,01$ & 0,29 & 0,15 & 0,06 & $-0,01$ & 0,10 & 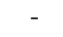 \\
\hline Q23 & 0,18 & 0,01 & 0,13 & 0,13 & 0,00 & 0,00 & $-0,22$ & 0,09 & $-0,12$ & 0,43 & 0,20 & 0,05 & 0,01 & 0,26 & 0,36 & 0,32 & 0,14 & 0,20 & 0,20 & 0,06 & 0,29 & $-0,06$ \\
\hline
\end{tabular}

fazendo-se com mais eficiência e eficácia os processos a partir da implantação dos preceitos da qualidade, obtém-se aumento nos lucros. Esta pesquisa ratificou essa relação.

A correlação entre as questões 5 e 8 (aumento da produtividade e melhoria no gerenciamento dos recursos), com valor 0,51 , pode ser explicada pelo fato de que a melhoria no gerenciamento dos recursos da produção acarreta em maior controle e melhoria de processos e, consequentemente, em diminuição da utilização de insumos e geração de desperdícios, resultando em aumento da produtividade da empresa.

As questões 6 e 8 (aumento do lucro e melhoria no gerenciamento dos recursos) apresentaram uma correlação de 0,55 , o que, obviamente, significa que melhorando o gerenciamento dos recursos ocorre o aumento da produtividade e a diminuição de desperdícios, como também explicado na parágrafo anterior, gerando assim aumento do lucro.

A correlação entre as questões 11 e 21 (melhoria da qualidade dos produtos pela certificação ISO 9001 e aumento da produtividade pela utilização de ferramentas da qualidade) obteve 0 valor 0,51. A melhoria da qualidade é um benefício auferido pela organização por meio da implantação de sistemas certificados ISO 9001, que, por sua vez, fomenta a utilização de programas e ferramentas da qualidade. Os dados desta pesquisa já demonstraram que ambos os elementos (ISO 9001 e ferramentas da qualidade) possibilitam a redução de erros e desperdícios, o que culmina no aumento da produtividade.

As questões 14 e 15 (ausência de indicadores dos processos e excessiva burocracia da norma ISO 9001) possuem uma correlação de 0,53. Uma possivel explicação para tal correlação é o fato de como grande parte das empresas participantes da pesquisa não possuía controle e monitoramento de indicadores antes da implantação do SGQ 1SO 9001, relataram esse fato como uma dificuldade, ou seja, alegam que o processo de certificação, que exige a instituição desses mecanismos, é demasiadamente burocrático.

A correlação entre as questões 18 e 21 (melhoria na gestão de recursos utilizados e aumento da produtividade promovida pela utilização de ferramentas da qualidade), com valor de 0,80, pode se dar em função do fato que a utilização das ferramentas da qualidade no controle e melhoria de processos permite melhor gerenciamento dos recursos e, por conseguinte, aumento da produtividade.

A partir do teste qui-quadrado, verificou-se uma relação estatisticamente significativa (valor : $p=0,025)$ entre o escopo de certificação e os benefícios auferidos, no sentido de que as empresas que tendem a discordar dos benefícios 
apresentados na literatura possuem certificação ISO 9001 com escopo completo e aquelas que concordam possuem, em sua maioria, escopo parcial. A Tabela 2 ilustra esses resultados.

Uma possível explicação para tal relação seja a maior complexidade para se gerenciar o sistema da qualidade ISO 9001 com escopo completo, tendo em vista o grande número de processos, documentos, indicadores e treinamentos a ele associados a serem controlados e continuamente melhorados, o que pode reduzir a intensidade dos resultados que poderiam advir.

Empresas de todos os portes discordaram que os programas e ferramentas da qualidade geram dificuldades consideráveis, contudo aquelas de porte mediano apresentaram um escore médio $(2,4)$ significativamente superior (valor : $p=0,011$ ) às demais (grandes $=1,72$ e pequenas $=1,67$ ), conforme Tabela 3.

As empresas de pequeno porte, apesar de, em geral, não terem o capital disponível ideal para investir em sistemas da qualidade, possuem processos mais simples e estrutura física e organizacional menor, o que facilita o gerenciamento dos elementos da qualidade. Já as grandes, mesmo com processos e sistemas mais complexos, apresentam fôlego financeiro para investir em consultorias, treinamento de multiplicadores e infraestrutura. As empresas de médio porte situam-se entre essas duas e, portanto, enfrentam problemas relacionados à disponibilidade de recursos e complexidade da estrutura e dos processos.

Tabela 2. Resultados da relação entre escopo da certificação vs. benefícios auferidos.

\begin{tabular}{lccc}
\hline & $\begin{array}{c}\text { Escopo } \\
\text { parcial } \\
(\%)\end{array}$ & $\begin{array}{c}\text { Escopo } \\
\text { completo } \\
(\%)\end{array}$ & $\begin{array}{c}\text { Total } \\
(\%)\end{array}$ \\
\hline Discordância completa & - & - & - \\
Discordância parcial & 22,2 & 77,8 & 100,0 \\
Não concorda/nem discorda & 42,9 & 57,1 & 100,0 \\
Concordância parcial & 88,9 & 11,1 & 100,0 \\
Concordância completa & 66,7 & 33,3 & 100,0 \\
\hline
\end{tabular}

Teste qui-quadrado; valor : $p=0,025$.

Tabela 3. Dificuldades em função do porte da empresa.

\begin{tabular}{cccc}
\hline Porte & Empresas (\%) & Média & Desv. padrão \\
\hline Grande & 57,63 & 1,72 & 0,67 \\
Médio & 26,70 & 2,40 & 0,70 \\
Pequeno & 15,67 & 1,67 & 0,52 \\
\hline
\end{tabular}

Teste não paramétrico de Kruskal-Wallis; valor : $p=0,012$.

\section{Conclusão}

Os sistemas de gestão da qualidade com base na norma ISO 9001 e os programas e ferramentas da qualidade representam importantes diferenciais para as empresas, pois proporcionam benefícios de diversas ordens (tanto internos como externos) conforme os dados apresentados neste trabalho. $\mathrm{Na}$ verdade, isto ratificou o que já era relatado na teoria científica, evidenciando que as bases deste sistema são aplicáveis às mais diversas realidades.

A amostra de empresas utilizadas nesta pesquisa é composta por empresas de serviços e de manufatura, porém observa-se uma quantidade muito inferior de organizações de serviços em relação à quantidade de organizações de manufatura. Será este um indicativo de que a norma ISO 9001 ainda continua mais atraente e apropriada às empresas de manufatura? Esta pesquisa não permite que essa questão seja esclarecida, e nem era o objetivo deste trabalho, mas cabe deixar esse questionamento para que pesquisas futuras o respondam.

0 objetivo deste trabalho era verificar as principais características do processo de certificação ISO 9001, seus benefícios, suas dificuldades e quais programas e ferramentas da qualidade eram utilizados em empresas do interior do Estado de São Paulo. Acredita-se que ele foi efetivamente alcançado com os dados e as análises feitas na seção 6 deste texto.

Pode-se citar, pelos resultados obtidos nesta pesquisa, que a certificação 1SO 9001 gera benefícios significativos às organizações, tais como: melhoria dos processos internos e dos seus produtos, aumento da satisfação dos clientes, diminuição do número de não conformidades e de devoluções, aumento da produtividade e do lucro, melhoria no gerenciamento dos recursos e valorização da imagem da empresa no mercado.

A pesquisa ratifica a importância da utilização dos programas e ferramentas da qualidade como forma de as empresas se adequarem melhor aos requisitos da norma ISO 9001, o que está gerando consideráveis diferenciais competitivos. Observou-se que $\mathrm{o}$ uso desses instrumentos (programas e ferramentas da qualidade) aumenta a satisfação dos clientes, aprimora a gestão dos recursos, melhora a produtividade, além de melhorar o monitoramento do desempenho da qualidade e a identificação e solução de problemas.

As dificuldades de desenvolvimento e implantação desses sistemas não se confirmaram para a amostra pesquisada. Apenas a resistência à mudança ficou com escore 3,10 , podendo ser considerada neutra, ou seja, os respondentes nem 
concordam nem discordam dela. Esse fato pode estar relacionado com o alto índice de utilização de consultorias especializadas para implantação do sistema ISO 9001 e com a alta utilização de times da qualidade para auxiliar na implantação e manutenção do sistema pelas empresas pesquisadas.

Destacam-se como principais limitações desse trabalho a restrição à extrapolação dos seus resultados para outras regiões, tendo em vista o seu recorte geográfico no interior do Estado de São Paulo e o fato de os questionários terem sido majoritariamente respondidos pelos responsáveis da direção (RDs) desses sistemas. Eles certamente têm uma visão mais abrangente e realista da situação, mas também podem ser tendenciosos por estarem respondendo sobre fatos diretamente relacionados ao produto de suas atividades, o que foi, de certa forma, minimizado pela análise estatística dos dados.

Por fim, ressalta-se que esta pesquisa apresenta um panorama geral sobre o tema e gerou informações que podem servir de base para outros trabalhos complementares e/ou mais específicos: em outras regiões, em diferentes setores industriais ou ainda complementando e aprofundando os resultados aqui obtidos.

Agradecemos à CAPES pelo auxílio na realização da pesquisa.

\section{Referências}

AHMED, S.; HASSAN, M. Survey and case investigations on application of quality management tools and techniques in SMls. International Journal of Quality \& Reliability Management, v. 20, n. 7, p. 795-826, 2003. http://dx.doi.org/10.1108/02656710310491221

ALSALEH, N. A. Application of quality tools by the Saudi food industry. The TQM Magazine, v. 19, n. 2, p. 150-161, 2007. http://dx.doi.org/10.1108/09544780710729999

ARUMUGAM, V.; 001, K. B.; FONG, T. C. TQM practices and quality management performance: an investigation of their relationship using data from 1S0 9001:2000 firms in Malaysia. The TQM Magazine, v. 20, n. 6, p. 636-650, 2008. http://dx.doi.org/10.1108/17542730810909383

ASSOCIAÇÃO BRASILEIRA DE NORMAS TÉCNICAS. 150 9001: 2008: Sistema de gestão da qualidade: requisitos. Rio de Janeiro: ABNT, 2008.

BAMFORD, D. R.; GREATBANKS, R. W. The use of quality management tools and techniques: a study of application in everyday situations. International Journal of Quality \& Reliability Management, v. 22, n. 4, p. 376-392, 2005. http://dx.doi.org/10.1108/02656710510591219

BATTIKHA, M. G. Quality management practice in highway construction. International Journal of Quality \& Reliability Management, v. 20, n. 5, p. 532-550, 2003. http://dx.doi. org/10.1108/02656710310476516

BHUIYAN, N.; BAGHEL, A. An overview of continuous improvement: from the past to the present. Management Decision, v. 43, n. 5, p. 761-771, 2005.
CARNEVAlli, J. A.; MIGUEL, P. A. C.; CAlARGE, F. A. Proposta de um modelo conceitual para minimizar as dificuldades no uso do QFD. Revista Produção, v. 18, n. 1, p. 126-141, 2008.

CHILESHE, N. Quality management concepts, principles, tools and philosophies: a valid methodology for deployment within UK construction-related SMEs. Journal of Engineering, Design and Technology, v. 5, n. 1, p. 49-67, 2007. http://dx.doi.org/10.1108/17260530710746605

CLAVER, E.; TARI, J. J. The individual effects of total quality management on customers, people and society results and quality performance in SMEs. Quality and Reliability Engineering International, v. 24, n. 2, p. 199-211, 2008. http://dx.doi.org/10.1002/qre.885

DEPEXE, M. D.; PALADINI, E. P. Benefícios da implantação e certificação de sistemas de gestão da qualidade em empresas construtoras. Revista Gestão Industrial, v. 4, n. 2, p. 145-161, 2008.

DONNELLY, M. et al. Assessing the quality of police services using Servqual. Policing: An International Journal of Police Strategies \& Management, v. 29, n. 1, p. 92-105, 2006.

DICK, G. P. M.; HERAS, 1.; CASADESÚS, M. Shedding light on causation between 1SO 9001 and improved business performance. International Journal of Operations \& Production Management, v. 28, n. 7, p. 687-708, 2008. http://dx.doi.org/10.1108/01443570810881811

FISHER, M. Process improvement by poka-yoke. Work Study, v. 48, n. 7, p. 264-266, 1999. http://dx.doi. org/10.1108/00438029910294153

GALBINSK1, J. ISO publica nova edição da 1SO 9001. Banas Qualidade, n. 199, p. 9, 2008.

GALDÁMEZ, E. V. C.; CARPINETTI, L. C. R., GEROLAMO, M. C. Proposta de um sistema de avaliação do desempenho para arranjos produtivos locais. Gestão \& Produção, v. 16, n. 1, p. 133-151, 2009. http://dx.doi.org/10.1590/S0104530X2009000100013

GARRATT, O. ISO 9001: 2000 and managing change in a South African law firm library. Performance Measurement and Metrics, v. 8, n. 3, p. 189-196, 2007. http://dx.doi. org/10.1108/14678040710841063

GONZALEZ, R. V. D.; MARTINS, M. F. Melhoria contínua no ambiente ISO 9001:2000: estudo de caso em duas empresas do setor automobilístico. Revista Produção, v. 17, n. 3, p. 592-603, 2007.

GRAEL, P. F. F.; OLIVEIRA, 0. J. Sistemas certificáveis de gestão ambiental e da qualidade: práticas para integração em empresas do setor moveleiro. Gestão \& Produção, v. 20 , n. 1 , p. $30-41,2010$

GUPTA, A. Quality management practices of 150 vs non1SO companies: a case of Indian industry. Industrial Management \& Data Systems, v. 100, n. 9, p. 451-5, 2000. http://dx.doi.org/10.1108/02635570010358357

HAGEMEYER, C.; GERSHENSON, J. K.; JOHNSON, D. M. Classification and application of problem solving quality tools: a manufacturing case study. The TQM Magazine, v. 18, n. 5, p. 455-483, 2006. http://dx.doi. org/10.1108/09544780610685458

HEUVEL, J.V.D. et al. An ISO 9001 quality management system in a hospital: bureaucracy or just benefits? International Journal of Health Care Quality Assurance, v. 18, n. 5, p. 361-36, 2005. http://dx.doi.org/10.1108/09526860510612216

INSTITUTO BRASILEIRO DE GEOGRAFIA E ESTATÍSTICA 1BGE. Disponível em: <http://www.ibge.gov.br>. Acesso em: 01 out. 2009a.

INSTITUTO NACIONAL DE METROLOGIA, NORMALIZAÇÃO E QUALIDADE INDUSTRIAL - INMETRO. Disponível em <www.inmetro.gov.br>. Acesso em: 03 maio 2009b. 
IVANOVIC, M. D.; MAJSTOROVIC, V. D. Model developed for the assessment of quality management level in manufacturing systems. The TQM Magazine, v. 18, n. 4, p. 410-423, 2006. http://dx.doi.org/10.1108/09544780610671075

JOHANSSON, P. et al. Variation mode and effect analysis: a practical tool for quality improvement. Quality and Reliability Engineering International, v. 22, n. 8, p. 865-876, 2006. http://dx.doi.org/10.1002/qre.773

JURAN, J. M.; GRYNA, F. M. Controle da qualidade: handbook - conceitos, políticas e filosofia da qualidade. São Paulo: Makron/McGraw-Hill, 1991.

KANUNGO, S.; BHATNAGAR, V. V. Beyond generic models for information system quality: the use of interpretive structural modeling (ISM). Systems Research and Behavioral Science, v. 19, n. 6, p. 531-549, 2002. http://dx.doi.org/10.1002/sres.476

KHANNA, H. K.; LAROIYA, S. C.; SHARMA, D. D. Quality management in Indian manufacturing organizations: some observations and results from a pilot survey. Brazilian Journal of Operations \& Production Management, v. 7, n. 1, p. 141-162, 2010.

KHANNA, V. K. 5 "S" and TQM status in Indian organizations. The TQM Journal, v. 21, n. 5, p. 486-501, 2009. http://dx.doi.org/10.1108/17542730910983407

KILBOURNE, W. E. Globalization and development: an expanded macromarketing view. Journal of Macromarketing, v. 24, n. 2, p. 122-135, 2004. http://dx.doi.org/10.1177/0276146704269303

LADHARI, R. A review of twenty years of servqual research. International Journal of Quality and Services Sciences, v. 1, n. 2, p. 172-198, 2009. http://dx.doi. org/10.1108/17566690910971445

LAGROSEN, S. Quality management and environment: exploring the connections. International Journal of Quality \& Reliability Management, v. 24, n. 4, p. 333-346, 2007. http://dx.doi.org/10.1108/02656710710740527

LAGROSEN, S.; LAGROSEN, Y. Quality configurations: a contingency approach to quality management. International Journal of Quality \& Reliability Management, v. 20, n. 7, p. 759-773, 2003. http://dx.doi.org/10.1108/02656710310491203

LAGROSEN, Y.; LAGROSEN, S. The effects of quality management: a survey of Swedish quality professionals. International Journal of Operations \& Production Management, v. 25, n. 10, p. 940-952, 2005.

LAGROSEN, Y.; BACKSTRON, 1,; LAGROSEN, S. Quality management and health: a double connection. International Journal of Quality \& Reliability Management, v. 24, n. 1, p. 49-61, 2007. http://dx.doi. org/10.1108/02656710710720321

LAKHAL, L.; PASIN, F.; LIMAM, M. Quality management practices and their impact on performance. International Journal of Quality \& Reliability Management, v. 23 n. 6, p. 625-646, 2006. http://dx.doi. org/10.1108/02656710610672461

LIN, C. C.; LUH, D. B. A vision-oriented approach for innovative product design. Advanced engineering informatics, v. 23, p. 191-200, 2009. http://dx.doi.org/10.1016/j. aei.2008.10.005

LYU JUNIOR. J.; CHANG, S. Y.; CHEN, T. L. Integrating RFID with quality assurance system - framework and applications. Expert Systems with Applications, v. 36, p. 10877-10882, 2009. http://dx.doi.org/10.1016/j. eswa.2009.01.082

MADY, M. T. Quality management practices: an empirical investigation of associated constructs in two Kuwaiti industries. International Journal of Quality \&
Reliability Management, v. 26, n. 3, p. 214-233, 2009. http://dx.doi.org/10.1108/02656710910936708

OLIVEIRA, A.; OLIVEIRA, $0 . \quad$ J. Diretrizes gerais para implantação de sistemas de gestão da segurança e saúde no trabalho. Revista Gestão Industrial, v. 4, n. 3, p. 1-17, 2008.

OLIVEIRA, 0. J. Modelo de gestão para pequenas empresas de projeto de edifícios. Tese (Doutorado em Engenharia)Escola Politécnica, Universidade de São Paulo, São Paulo, 2005.

OLIVEIRA, G. T.; MARTINS, R. A. Efeitos da adoção do modelo do Prêmio Nacional da Qualidade na medição de desempenho: estudos de caso em empresas ganhadoras do prêmio. Gestão \& Produção, v. 15, n. 2, p. 247-259, 2008. http://dx.doi.org/10.1590/S0104-530X2008000200004

OZGUR, C.; MEEK, G.; TOKER, A. The impact of ISO certification on the levels of awareness and usage of quality tools and concepts: a survey of Turkish manufacturing companies. Quality Management Journal, v. 9, n. 2, p. 57-69, 2002.

POKSINSKA, B.; EKLUND, J. A. E.; DAHLGAARD, J. J. ISO 9001:2000 in small organizations. International Journal of Quality \& Reliability Management, v. 23, n. 5, p. 490-512, 2006. http://dx.doi.org/10.1108/02656710610664578

ROBSON, A.; MITCHELL, E. CSR performance: driven by TQM implementation, size, sector? International Journal of Quality \& Reliability Management, v. 24, n. 7, p. 722-737, 2007. http://dx.doi.org/10.1108/02656710710774692

ROMANO, P. $1 S 0$ 9000: what is its impact on performance? Quality Management Journal, v. 7, n. 3, p. 38-56, 2000.

SIGALA, M. The ASP-Qual model: measuring ASP service quality in Greece. Managing Service Quality, v. 14, n. 1, p. 103-114, 2004. http://dx.doi.org/10.1108/09604520410513703

SRDOC, A.; SLUGA, A.; BRATKO, 1. A quality management model based on the "deep quality concept". International Journal of Quality \& Reliability Management, v. 22, n. 3, p. 278-302, 2005. http://dx.doi.org/10.1108/02656710510582499

TONINI, A. C.; CARVALHO, M. M.; SPINOLA, M. M.; Contribuição dos modelos de qualidade e maturidade na melhoria dos processos de software. Revista Produção, v. 18, n. 2, p. 275-286, 2008.

THIA, C. W. et al. An exploratory study of the use of quality tools and techniques in product development. The TQM Magazine, v. 17, n. 5, p. 406-424, 2005. http://dx.doi. org/10.1108/09544780510615924

UENO, A. Which management practices are contributory to service quality? International Journal of Quality \& Reliability Management, v. 25, n. 6, p. 585-603, 2008. http://dx.doi.org/10.1108/02656710810881890

VENKATRAMAN, S. A framework for implementing TQM in higher education programs. Quality Assurance in Education, v. 15, n. 1, p. 92-112, 2007. http://dx.doi. org/10.1108/09684880710723052

ZENG, S. X.; TIAN, P.; SHI, J. J. Implementing integration of ISO 9001 and ISO 14001 for construction. Managerial Auditing Journal, v. 20, n. 4, p. 394-407, 2005. http://dx.doi.org/10.1108/02686900510592070

$\mathrm{ZU}, \mathrm{X}$. Infrastructure and core quality management practices: how do they affect quality? International Journal of Quality \& Reliability Management, v. 26, n. 2, p. 129-149, 2009. http://dx.doi.org/10.1108/02656710910928789 


\section{A study on the use of quality systems, programs and tools in companies of interior of São Paulo State}

\section{Abstract}

The development and implementation of quality management systems and the use of quality tools and programs are some of the most widely used options by managers to increase the competitiveness of their companies. Thus, the goal of this paper is to present the result of a research type survey which analyzed the main characteristics of the 1SO 9001 certification process, its benefits and difficulties and which quality programs and tools are used in 236 company headquartered in the interior of São Paulo State. The survey showed that the ISO 9001 certification generates significant benefits to organizations, such as: improved internal processes and their products; increased customer satisfaction; decreased number of non-conformities and discards; increased productivity and profit; improved resources management and improved company image on the market. It also ratified the importance of using quality tools and programs as a way for companies to meet the 1509001 requirements. The difficulties to develop and implement these systems are not confirmed in the sample studied. Only the resistance to change, within all the cases presented, was highlighting by the companies.

\section{Keywords}

Quality management system. Quality programs. Quality tools. ISO 9001. Interior of the Sao Paulo State.

\section{Anexo 1. Questionário.}

\section{Seção A - Identificação e caracterização da empresa}

Nome da empresa:

Endereço:

Site:

Respondente:

Cargo:

E-mail:

Telefone:

- Porte da empresa:

() Microempresa - Até 9 empregados () Pequena empresa - De 10 a 99 empregados

( ) Média empresa - De 100 a 499 empregados ( ) Grande empresa - Mais de 500 empregados

- Ramo de atividade:

- Ano da certificação 1SO 9001:

- Escopo da certificação 1S0 9001:
() Parcial
() Total

- Utilizou consultoria externa para obter a certificação 1SO 9001 ?
( ) Sim
( ) Não

- Possui times da qualidade?
() Sim
( ) Não

- Tempo para certificação ISO 9001:

() Até 6 meses

() De 13 meses até 18 meses
() De 7 meses até 12 meses

() Acima de 19 meses

- Programas e ferramentas da qualidade utilizados na empresa
() Diagrama de lshikawa
() $5 \mathrm{~S}$
() PDCA
( ) Gráfico de Pareto
() CEP
() $5 \mathrm{~W} 1 \mathrm{H}$ ou $5 \mathrm{~W} 2 \mathrm{H}$
() Brainstorming
() FMEA
( ) Histograma
( ) Benchmarking
() Check list
( ) Servqual
( ) QFD
( ) Setup rápido
() Seis sigma
() Poka yoke 


\section{Seção B - Sistema de gestão da qualidade}

- 0 sistema de gestão da qualidade promove aumento da satisfação dos clientes.

- 0 sistema de gestão da qualidade promove melhoria no controle dos processos da empresa.

- O sistema de gestão da qualidade promove diminuição de não conformidades dos processos e produtos.

- 0 sistema de gestão da qualidade promove diminuição no número de devoluções de produtos.

- 0 sistema de gestão da qualidade promove aumento da produtividade da empresa.

- $\quad 0$ sistema de gestão da qualidade promove aumento do lucro da empresa.

- 0 sistema de gestão da qualidade promove melhoria na imagem da empresa.

- 0 sistema de gestão da qualidade promove melhoria no gerenciamento dos recursos.

- 0 sistema de gestão da qualidade promove melhoria na capacitação dos funcionários.

- 0 sistema de gestão da qualidade promove motivação ao trabalho em equipe.

- 0 sistema de gestão da qualidade promove melhoria na qualidade dos produtos.

- Houve resistência dos funcionários durante a implantação do SGQ.

- A existência de não conformidades representou uma dificuldade significativa para a empresa implantar o SGQ.

- A ausência de indicadores dos processos representou uma dificuldade significativa para a empresa implantar o SGQ.

- A norma ISO 9001 representou burocracia excessiva para os processos da empresa.

- Houve pouco envolvimento da alta direção para a implantação do SGQ.

\section{Seção C - Utilização de programas e ferramentas da qualidade}

- A utilização de programas e ferramentas da qualidade promove aumento da satisfação dos clientes.

- A utilização de programas e ferramentas da qualidade promove melhoria na gestão de recursos utilizados.

- A utilização de programas e ferramentas da qualidade promove melhoria na medição e monitoramento do desempenho da qualidade.

- A utilização de programas e ferramentas da qualidade promove melhoria da identificação e solução de problemas.

- A utilização de programas e ferramentas da qualidade promove aumento da produtividade.

- A utilização de programas e ferramentas da qualidade promove melhoria no ambiente de trabalho.

- Houve resistência dos funcionários para a utilização de programas e ferramentas da qualidade. 